\title{
Review
}

\section{Nanotechnology and its Application in Animal Production: A Review}

\author{
Haben Fesseha, DVM, MVSc ${ }^{\prime *}$;Tadesse Degu, DVM²;Yonas Getachew, DVM³ \\ 'Department of Veterinary Surgery and Diagnostic Imaging, School of Veterinary Medicine, Wolaita Sodo University, P. O. Box I 38, Wolaita Sodo, Ethiopia \\ ${ }^{2}$ College of Veterinary Science, Mekelle University, P. O. Box 2084, Mekelle, Ethiopia \\ ${ }^{3}$ College of Veterinary Medicine, Addis Ababa University, P. O. Box 34, Bishoftu, Ethiopia
}

*Corresponding author

Haben Fesseha, MVSc, DVM

Assistant Professor, Department of Veterinary Surgery and Diagnostic Imaging, School of Veterinary Medicine, Wolaita Sodo University, P. O. Box I38, Wolaita Sodo, Ethiopia;Tel. +25I910737790; ORCID: 0000-0001-6516-3036; E-mail: tseyon.h@gmail.com

\section{Article information}

Received: June 15 ${ }^{\text {th }}$ 2020; Revised: August I ${ }^{\text {st }}, 2020$; Accepted: August 19 ${ }^{\text {th }}, 2020$; Published: September $3^{\text {rd }}, 2020$

\section{Cite this article}

Fesseha H, Degu T, Getachew Y. Nanotechnology and its application in animal production:A review. Vet Med Open J. 2020; 5(2): 43-50. doi: 10.17।40/VMOJ-5-I48

\section{ABSTRACT |}

Nanoparticles are small and have a large surface-to-volume ratio, which gives them phenomenal, unique features. It is an emerging, multidisciplinary field that frequently employs new techniques and tools from diverse disciplines, including biology, engineering, chemistry, and medicine. Nanotechnology entities help to improve the solubility, absorbability, bioavailability, and half-life of conventional natural products. Nano-applications are used in poultry and animal production systems using available tools and techniques without affecting animal health and welfare. Nanotechnology is a smart technology in the field of biomedical engineering used for the diagnosis and treatment of different poultry diseases. This technology provides better solutions for various applications and poultry production that can help in reducing costs and improving the final product quality. Even though nanotechnology is one of the main novelties which have already been applied in poultry and other different areas, it is still in the initial stages of its development and it hampers the environment, animal, and people's health. Therefore, wide hazard assessments should be conducted to ensure the safety of the nanoproducts before making them immediate implementation for poultry/ani$\mathrm{mal} /$ or human use.

\section{Keywords}

Application; Health; Nanotechnology; Poultry; Production.

\section{INTRODUCTION}

A nimal productions in general and poultry production in particular play an important socio-economic role for sustainable development. By 2020, the poultry sector is expected to provide $40 \%$ of the world's total animal protein where the major demand being in the developing world. However, most communities lack the required husbandry skills, training, and opportunity to effectively improve their household chicken production. For the operation to be profitable, a good disease prevention program and product improvement are essential for the newly introduced chicks to avoid any future losses. ${ }^{1}$

For this, recent advancements in the field of biotechnology, molecular biology, genetics, and immunology revolutionized biomedical research and therapy in medical and veterinary fields. Sustained efforts have led to the development of many novel therapies and treatment modalities. ${ }^{2,3}$ Biotechnology is applied in various fields ranging from medicine to agriculture. Besides, the utilization of the technology needs the application of knowledge and techniques of biology to operate molecular, genetic, and cellular processes that help to manufacture different products and services. The welfare of animals, animal safety derived products, risks to the environment, human health, and industry consolidation are amongst the main concerns that are likely to extend from biotechnology to nanotechnology. ${ }^{4,5}$

Nanotechnology is a new scientific approach that study about the control of matter on an atomic and molecular scale, generally structures in the nanometer. This involves developing materials or devices on the nanometer scale and this helps to use materials and equipment at molecular levels that are capable of showing both physical and chemical properties of a substance. This unique feature of nanotechnology has the potential to transform the agricultural and food industry for the control and prevention of diseases, rapid detection of disease, improving the ability of plants to absorb nutrients, and so on. ${ }^{6-8}$ 
Nanosensors, nanomaterials, microfluidics, and bioanalytical are nanotechnology devices that are used to improve various conditions related to animal health, production, reproduction, treatment, and prevention of diseases. It can be concluded that nanotechnology research will reform the livestock sector by improving production systems. ${ }^{9}, 10$

Micro-minerals participate in several biochemical processes and are parts of many enzymes that are necessary for normal biochemical reactions. Recently trace minerals in the form of nanoparticles are effectively used to fulfill the requirement of minerals in the poultry diets. Since they are extremely small size and unique physical properties, the nanoparticles are likely to be different when compared to their conventional forms. As a feed additive, these are expected to have the advantage of better bioavailability, small dose rate, and stable interaction with other components. ${ }^{8,9,11,12}$

Feeding certain antibiotics at low-levels in poultry for an extended period is a common practice in the poultry industry to improve feed efficiency, improving growth performance, preventing some specific pathogenic microorganisms, and increasing some useful microorganisms in intestinal microflora over the years. ${ }^{13,14}$ But recently, infeed, antibiotics have been banned due to the potential development of antibiotic-resistant bacteria and their residues in poultry meat. After, that the researcher had attempted to find an alternative to have positive characteristics without negative effects. As a result, nutritionists are exploring alternatives such as medicinal plants, probiotics, prebiotics, and organic acids. In recent years, additives from nanotechnology in poultry nutrition are potentially enhancing the poultry production. ${ }^{15}$

Thus, the use of nanoparticles has been considered an alternate and effective approach that is eco-friendly and cost-effective for the control of pathogenic microbes and production improvement in poultry. ${ }^{16-19}$

\section{NANOTECHNOLOGY}

Nanotechnology (NT) is a new discipline of science that has led to novel and innovative approaches in many areas of medicine. Nanotechnology is the ability to quantify, manipulate, and form material at the level of nanoscale. The scale classically refers to the matter in the size range of $1-100 \mathrm{~nm}$, but it is often extended to include materials below $1 \mu \mathrm{m}$ in size. Key global challenges associated with animal production include environmental sustainability, human health, disease control, and food security. ${ }^{20}$

Nanoparticles retain unique properties. Consequently, these characteristic features of nanoparticles significantly improve the physical and chemical properties of materials. ${ }^{71,21}$

Nanotechnology has a tremendous potential to revolutionize the agriculture and livestock sector since it contributes a lot in the field of veterinary medicine and other areas of animal production. Nanotechnology also offers novel technologies in various fields such as veterinary physiology, animal reproduction, animal genetics, biotechnology, molecular and cellular biology. This al- lows researchers to handle biological constituents such as DNA, proteins, or cells in minute quantities usually nano-liters or picoliters. ${ }^{22}$

\section{Types of Nanomaterials}

Organic nanomaterials: Proteins, fat, and sugar molecules are organic nanomaterials. Organic nanoparticles are feeds derived from different feed sources such as nutraceuticals that provide health benefits. The nanoparticles incorporated into feeds include those engineered to provide encapsulation systems. For instance; micelles, liposomes, for delivery of feed ingredients and those tailored for use in feed packagings such as biosensors, identification markers, shelf-life extenders, and antimicrobials. ${ }^{23}$

Organic nanoparticles occasionally referred to as nanocapsules while used as vehicles for delivery of essential nutrients or pharmaceuticals and are likely to be used to enhance the nutrient value of feed-through improvement or alteration of feed functionality. These nanoparticles have been designed to deliver vitamins or other nutrients in feed without affecting the taste or appearance. Such nanoparticles encapsulate the nutrients and carry them via the gastrointestinal tract (GIT) into the bloodstream to increase their bioavailability. ${ }^{24}$

Inorganic nanomaterials: Inorganic nanomaterials are used for types of applications, for instance, nanoclay platelets are used for feed packaging in feed and feed additives; minerals such as silicon dioxide, calcium and magnesium; and silver nanoparticles for water purification or antimicrobial packaging or feed storage, zinc as a feed colorant. Titanium dioxide, a feed colorant used as a ultraviolet (UV) protection barrier in the feed packaging industry is an approved inorganic nanoparticle because it becomes transparent and also loses its ability to act as a feed colorant in its nanoform. ${ }^{13,22,25}$

The nanoparticles of silver are used as an antimicrobial agent. Nano-silver is used in fridge panels, storage boxes, packaging lines, and other surfaces that come into contact with feed during manufacture. Feed storage bins are being produced with silver nanoparticles embedded in the plastic which kills bacteria from any feed that is stored in the bins and minimizes the health risks. ${ }^{15}$

\section{Properties of Nanoparticles}

In practice, the physical, chemical, and biological properties of a substance are determined by the association of physicochemical phenomena that act on the matter. Those are such as gravitational force, inertia, friction, Brownian motion, electrostatic interactions, and electrical repulsion. One conventional substance in the metric scale suffers the action of all these phenomena at different levels. However, once a substance has its size reduced; the action of these forces changes. ${ }^{26}$

In addition, its surface area is drastically increased. Atoms become more stable at $100 \mathrm{~nm}$ especially, in relation to their metric form. Hence, only a smaller amount of energy is required to separate into nanoparticles. Then, a size-reduced substance can acquire new physical and chemical characteristics, with greater re- 
activity and solubility, according to the different environmental conditions. Nanoparticles and materials that contain nanoparticles remain protected from different types of bioactive agents and reactions such as oxidizing agents, enzymes, or chemical interaction with other molecules. This is due to the active ingredient of the nanoparticles has provided and increased their stability. $5,26,27$

Surface effects: The atoms of nanomaterials are less stable than those of larger structures since the energy required to join adjacent atoms is less. As a consequence of this, the fusion point of a given element changes. Nanoparticles diffuse more easily than solid particles and behave more like gas molecules in the air and being less subject to sedimentation than bigger particles. This may have implications also for the faster movement of nanoparticles in tissue. ${ }^{28}$

Quantum effects: Quantum points are a type of nanostructures, just a few nanometers in size that show a behavior similar to a single atom. The spatial arrangement of nanoparticles allows them to change their properties of elements. For instance, elements like magnetism, and metals like gold or platinum have such properties when they are in the form of nanoparticles. ${ }^{29}$

\section{NANOTECHNOLOGY IN POULTRY PRODUCTION}

\section{Potential Effect of Nanotechnology}

Nanotechnology is considered as a potential technology to revolutionize veterinary medicine, animal health, and other areas of animal production. In the field of veterinary medicine and poultry production, there is a growing interest in the application of nanotechnology and various compounds are used as a supplemental source of trace minerals $\left(\mathrm{Na}_{2} \mathrm{O}, \mathrm{MgO}, \mathrm{Al}_{2} \mathrm{O}_{3}, \mathrm{SiO}_{2}, \mathrm{~K} 2 \mathrm{O}, \mathrm{CaO}\right.$, $\mathrm{TiO}_{2}$, and $\mathrm{Fe}_{2} \mathrm{O} 3$ ) in diets. It is quite competent in new products and new processes developed to enhance the performance of the products, extend the product shelf-life and freshness as well as in getting better the safety and quality of food. ${ }^{30}$

Nanoform of supplementation increases the surface area which possibly could increase absorption and thereby utilization of minerals leading to a reduction in the number of supplements and ultimately reduction in feed cost. The growing concerns with regard to the potential contribution of phosphorus in poultry excreta on eutrophication of surface waters have led to increasing pressure to limit the amount of excess phosphorus in poultry ration and thus reduce the fecal output of phosphorus. Mineral nanoparticles will help to reduce the excretion of unutilized minerals minimizing the environmental pollution especially in large scale poultry farming. ${ }^{14}$

A research finding showed that an in ovo-injection of nano-silver nanoparticle during incubation has shown improvement of bone mineral concentration and cell-mediated immunity at the age day 14 and 21, respectively. Besides, the immune response especially the humoral immunity was higher in nano-silver treated eggs than the control one. In general, injection of nano-silver, thyme, and savory extracts into eggs during embryonic development has a great potentialto improve immune activities of broiler chickens without affecting the embryo and its hatchability. ${ }^{3,31}$
Nano-silver increases levels of blood alkaline phosphatase which is associated with bone formation in chicken. ${ }^{3,31}$ Copper is a vital mineral for vesicle matrix in the bone cell, preventing its premature crystallization and also implements an important role in the cross-linked network of collagen and elastin, which causes bone tensile strength and elasticity. Hence, the statistical analysis showed that the nano-silver treated groups have greater levels of ash, calcium, and copper in their bone as compared to the control group and this could be justified by the greater activity of alkaline phosphatase. $^{32}$

Nanotechnology can make poultry and meat products cost-effective with the natural properties and the differentiation in qualities of products can easily be made by nanotechnology-based cooling rates and also allow rapid and homogeneous techniques. The future application of nanotechnology depends on the collaborative production of poultry meat that ha better color, flavor, or nutrients. Many of the molecular structures that determine these characteristics are in the nanometer range and information on the source can play an important role in the poultry meat design, the purpose is to master over the characteristic of meat and its components in an intelligent manner by manipulating atoms individually and place them exactly where they are needed to produce the desired flavor and texture. ${ }^{11}$

Thus, nanotechnology can be applied in the production of nanoparticles which can be used in improving digestion and absorption as novel food additives. Applications of nanotechnology are ever more varied and specific, with a high potential for improving poultry production. Nanoparticle incorporation in animal nutrition studies greatly enhances the efficiency of growth and production of poultry. However, a great amount of research is still required to support the effectiveness, and mainly the safety of nanotechnology, avoiding any harm to the birds. ${ }^{33}$

\section{Application of Nanotechnology in Poultry Production}

Applications of nanomaterials are currently used for meat and food generally; including the use of NPs and nanomaterials as food ingredients/additives which are placed directly into food, or as a part of food packaging. The dissolving ability of fat-soluble additives in food products, improvement of taste, and reduction of the use of fat, salt, sugar, and preservatives can be achieved through the microencapsulating process. Reducing the salt level is especially important and presents a great challenge for the meat industry because, despite advantages, the use of salt has shortcomings since it is linked to hypertension and consequently increased the risk of cardiovascular disease. ${ }^{34}$

Currently, nanoparticles have a diverse application in medicine to transport drugs, heat, light or other substances to specific types of cells (such as cancer cells). Researchers across the world are also developing nanoparticles to defeat viruses. Even though nanoparticle does not directly act on the virus, they deliver an enzyme that prevents the replication of virus molecules in the host's circulatory system. There are efforts underway to develop oral administration of several different drugs using a variety of nanoparticles. ${ }^{22}$ 
Nanoparticles (NPs) show several novel characteristics of transport and uptake and exhibit higher absorption efficiencies. ${ }^{35}$ NPs can rout to the GIT in many ways such as ingestion directly from food and water and the administration of therapeutic nano-drugs (ingestion or swallow pathway) and their mechanism of actionis described below: 1 . Increase the surface area available to interact with biological support, 2. Prolong compound residence time in GIT, 3. Decrease influence of intestinal clearance mechanisms, 4. Penetrate deeply into tissues through fine capillaries, 5 . Cross epithelial lining fenestration (such as liver) 6. Enable efficient uptake by cells, and efficient delivery of active compounds to target sites in the body. ${ }^{14}$

Minute micelles (nano-capsules) are used as carriers for essential oils, flavor, antioxidants, coenzyme and vitamins, minerals, and phytochemicals to improve their bioavailability. Encapsulating the nanoparticles of active ingredients (minerals and micronutrients) to protect them from oxidation and getting to the taste receptor site, thus to reduce their undesirable off-tastes in the finished application. ${ }^{36}$

In the food industry application of liposomal nanovesicles for the encapsulation and delivery of nutrients and functional ingredients such as proteins, enzymes, flavors, and antimicrobial compounds were conducted. The size of minerals nanoparticles should be less than 100 nanometers to use it as feed additives and this allows the molecules to easily pass through the stomach wall and into body cells more quickly than ordinary minerals with larger particle size and effectively used to fulfill the requirement of minerals in the poultry feed in small dose so to increase their production performance (Figure 1). 3,27,37

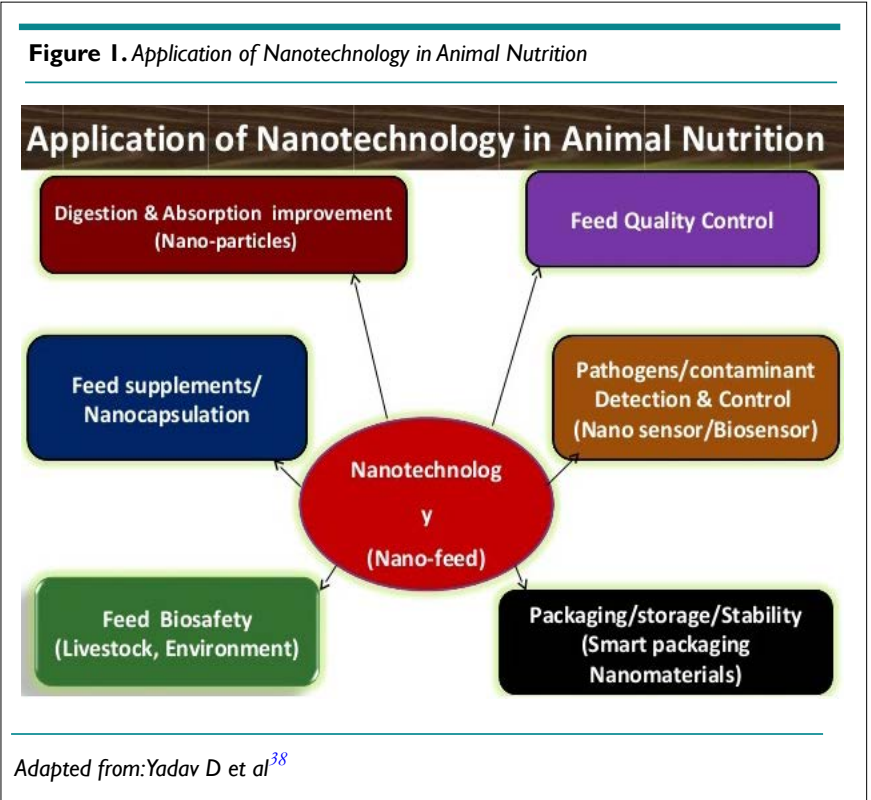

\section{NANOTECHNOLOGY IN POULTRY HEALTH|}

There are different important nanotechnology links to agriculture science and engineering as well as food systems. Among these, agricultural and food security systems, disease management delivery systems, new techniques for molecular and cellular biology, new materials for pathogen detection, and protection of the environment. ${ }^{39}$ Recently, increasing demand for healthy and safe food, high-risk of disease, and threats to agricultural production from changing weather patterns become the new constraint for the poultry production. ${ }^{13,40}$

Accordingly, disease control in animals is multifaceted, and the more traditional emergency products are required for preventive measures. In professional hospitals and homes, attention is being paid to veterinary needs. Antimicrobial products of plant origin are valuable, versatile, and safe and have a crucial and specific role in controlling bacterial diseases in animals. ${ }^{6,84}$

There are various smart components in nanostructures that allow us to provide capacity over certain biological barriers, such as skin, eye, brain, placenta, mucus, blood, extracellular matrix, cellular and subcellular organelles. Smart delivery systems can have multifunctional characteristics to successful targeting and they may also be time-controlled; spatially targeted; self-regulated; remotely regulated and pre-programmed. ${ }^{42}$

Silver (Ag), Copper $(\mathrm{Cu})$, Iron $(\mathrm{Fe})$, and Manganese dioxide $\left(\mathrm{MnO}_{2}\right)$ are metal nanocomposite were added to poultry feeds to increase the quantity and quality of productivity of laying hens. Hence, this predominates the effect of salts of the metals, which is characterized by increased levels of egg-laying during the experiment in poultry. Introduction of metals as additives in macro and nanoscale form causes changes in the $\mathrm{pH}$-level of egg white and yolk but within the norms regulated by the requirements hen's eggs for human consumption. ${ }^{43-45}$

Functionalized NPs-conjugated to monoclonal antibodies have been used to rapidly and specifically detect the respiratory syncytial virus in vitro and in vivo. Hence, this fills the gap between the recent detection assay of a wide variety of virus types and the necessity for more rapid and sensitive detection of viral agents so that it can offer direct, rapid, and sensitive detection of viruses. ${ }^{46,47}$ Likewise, protein cage nanoparticles (PCN) free of any specific viral antigens were administered to mice and all mice were protected against both sub-lethal and lethal doses of two type of influenza viruses, that is a mouse-adapted coronavirus and mouse pneumovirus. All PCN treated showed rapid production of viral-specific antibody and removal of the virus and this in turn, increases the virus survival rate and significant decreases in morbidity and lung damage. ${ }^{7,48}$

Cell-mediated immunity, in terms of mean skin thickness sensitive to phytohemagglutinin, was significantly enhanced in chicks given the nano-silver treatment compared with the control and hence their immunity was improved by nano-silver diets. This cell-mediated immunity does not relate to body antibodies; rather it is an immune response that emerged from the action of phagocytes, natural killer cells, antigen-specific cytotoxic T-lymphocytes, and various cytokines against antigen activation. ${ }^{49}$

In nano-silver treated chicken, the lower weights of thyme and savory treatments can be associated with the antimicrobial properties of these ingredients that modify the microbial 
inhabitants in poultry caecum. Consequently, lymphoid organs as lymphoid organs were decreased with increasing nano-silver, thyme, and savory levels in diets. It is established that microorganisms in the gastrointestinal tract have a key role in the growth and development of lymphoid organs. In addition to the antimicrobial characteristic, nano-silver also can act as an agent that makes oxygen available and reduce strictly anaerobic microorganisms and consequently lymphoid organ growth. ${ }^{28}$ The action of silver might be due to the intake of silver ions by bacterial cells and the production of reactive oxygen molecules that finally inhibit the bacterial respiration..$^{50-52}$

In addition, NPs in poultry had given to remove the Campylobacter (harmful for human consumption not for birds). When the nanoparticles added feed is ingested by the birds these nanoparticles attach to Campylobacter, ensures its excretion. Nanoparticles would be specifically designed to attach to molecules that exist on the surface of Campylobacter and removed from chicken before they reach humans. Such nanoparticles are called biofunctionalized nanoparticles which have been developed as an alternative to mannose through which Campylobacter jejuni attaches to the epithelial cells. ${ }^{53}$

\section{STATUS AND FUTURE PROSPECTS OF NANOTECHNOLOGY}

In the upcoming years, nanotechnology research will reform the science and technology of animal health and will help to boost up the livestock production. Proponents of nanotechnology consider this technology as one of the most powerful tools in modern society; it has made a revolutionary impact on every aspect of human life. Looking at the speed of advancement of nanomedicine, particularly the utilization of various nanoparticles in the prevention, diagnosis, and treatment of a complex disease like cancer, one can predict that this cutting-edge technology will be on our doorstep soon..$^{54}$

In the future, it can be conceived that bacterial infections can be eliminated in the patient within a few minutes, instead of using treatment with antibiotics for weeks. With the advancement in technology, we can expect to generate the capability to perform surgery at a cellular level, thereby removing individual diseased cells and even repairing defective portions of the individual cells. Several nanotechnology-based products are already in the market and many are under development or in experimental stages.,

Apart from the nanochemo prevention side of nanotechnology, studies have shown that a nanotechnology is a plausible approach for diagnosis, imaging, and therapeutics. Considerable research is now being devoted to nanoparticles-based drug delivery. Several nanotechnology-based constructs are currently in clinical or preclinical development and several of these are already approved by the food and drug authority. Advancements in the utilization of nanotechnology might help us to achieve the higher concentrations of the natural products necessary for efficacy against various diseases. It is assumed that a cure for cancer will be available and it is also anticipated that nanotechnology will be a $\$ 1$
USD trillion industry, with most of the impact-focused on healthcare and cancer therapy. ${ }^{55}$

While research and development in nanotechnology are quite limited in most developing countries, there will be increasing opportunities to import nanoproducts and processes. Besides, selfreplicating nano-machinery, fabrics that can react to the environment, and sensors that can detect pollutants and airborne toxins are other potential future applications. Moreover, nano-sensory surveillance devices will be used to track the movement of people and vehicles. Furthermore, nanotechnology will play a leading role in global veterinary practice. ${ }^{7,42}$

\section{CHALLENGES AND LIMITATIONS OF NANOTECHNOLOGY}

Nanotechnology provides a new insight to discover better diagnosis, prevention, and treatment of different diseases in poultry, unlike the previous conventional technologies. Although the benefits associated with the use of nanoparticulate systems in order to optimize the productive performance and treat diseases, it is largely accepted that some nanoparticles (like metal nanoparticles) can elicit toxic and deleterious side effects towards living organisms. As with all new technologies new risks might appear that we have not thought about yet, underlining the need for continuous and dynamic risk reviews. ${ }^{56}$

The effects of exposure to engineered nanoparticles may be different from the effects caused by naturally occurring nanoparticles. Engineered nanoparticles may be better to evade the body's defenses because of their size or protective coatings. Moreover, the health and environmental risks raised due to the exposure to engineered nanoparticles need further study. ${ }^{21,57}$

The risks and safeties are related to free nanoparticles will concern only a fraction of the applications of nanotechnologies. In most applications, nanoparticles will be embedded in the final product and therefore not come into direct contact with workers, animals, consumers, or the environment. There are different challenges related to nanotechnologies such as environmental risks due to release of nanoparticles into the environment, human (workers and consumers) may also suffer from safety risks and futuristic risks like human enhancement and self-replications of nanomachines, business risks involved with the marketing of nanotechnology-enabled products and risks related to the protection of intellectual property are identified. ${ }^{20,58}$

\section{CONCLUSION}

Nanotechnology holds a major promise for poultry, veterinary medicine, and other areas of animal production. The nanotechnologies are designed and used for various purposes through characterization, production, and application of structures, devices, and systems by controlling shape and size on a nanometer scale. NTs can enhance food properties, easily transport nutrients and flavors into the body, extended its shelf-life, improved production processes, and health status of poultry. Although there are benefits 
related to the use of nanoparticle for improving the productive performance and treat diseases in poultry, it is largely accepted that some nanoparticles can provoke toxic and harmful side effects towards living organisms upon immediate implementation. Besides the potential of nanotechnology in poultry production cannot be fully appreciated yet and there are limited number of studies carrying out on the use of nanoparticles for poultry production and health. Therefore, further study should be conducted on nanotechnology to a detailed evaluation of its productive performance and health status in poultry. Besides, safety and its risk should be assessed before the direct implementation of nanoparticles.

\section{CONFLICTS OF INTEREST}

The authors declare that they have no conflicts of interest.

\section{REFERENCES}

1. Moges F. Indigenous chicken production and marketing systems in Ethiopia: Characteristics and opportunities for market-oriented development. Web site. http://www.fao.org/tempref/AG/Reserved/DAD-Net/Poultry_synthesis_WP24.pdf. Accessed June 14, 2020.

2. Dhama K, Chakraborty S, Mahima, Wani MY, Verma AK, Deb $\mathrm{R}$, et al. Novel and emerging therapies safeguarding health of humans and their companion animals: A review. Pak J Biol Sci. 2013; 16(3): 101-111. doi: 10.3923/pjbs.2013.101.111

3. Tatli Seven P, Seven I, Gul Baykalir B, Iflazoglu Mutlu S, Salem AZ. Nanotechnology and nano-propolis in animal production and health: an overview. Italian Journal of Animal Science. 2018; 17(4): 921-930. doi: 10.1080/1828051X.2018.1448726

4. Fakruddin M, Hossain Z, Afroz H. Prospects and applications of nanobiotechnology: A medical perspective. Journal of Nanobiotechnology. 2012; 10(1): 1-8. doi: 10.1186/1477-3155-10-40

5. Huang S, Wang L, Liu L, Hou Y, Li L. Nanotechnology in agriculture, livestock, and aquaculture in China. A review. Agron. Sustain. Dev. 2015; 35(2): 369-400. doi: 10.1007/s13593-014-0274-х

6. Meena NS, Sahni YP, Thakur D, Singh RP. Applications of nanotechnology in veterinary therapeutics. Journal of Entomology and Zoology Studies. 2018; 6(2): 167-175.

7. Sah SK, Kaur A, Wani S. Nanobiotechnology: changing horizons of science. Biolife. 2014; 2(3): 905-916.

8. Sekhon BS. Nanotechnology in agri-food production: An overview. Nanotechnol Sci Appl. 2014; 7: 31-53. doi: 10.2147/NSA. S39406

9. Kroubi M, Daulouede S, Karembe H, Jallouli Y, Howsam M, Mossalayi D, et al. Development of a nanoparticulate formulation of diminazene to treat African trypanosomiasis. Nanotechnology. 2010; 21(50): 505102. doi: 10.1088/0957-4484/21/50/505102
10. Tarafdar J, Sharma S, Raliya R. Nanotechnology: Interdisciplinary science of applications. African Journal of Biotechnology. 2013; 12(3): 219-226. doi: 10.5897/AJB12.2481

11. Muktar Y, Bikila T, Keffale M. Application of nanotechnology for animal health and production improvement: A review. World Appl Sci J. 2015; 33(10): 1588-1596. doi: 10.5829/idosi. wasj.2015.33.10.96253

12. Verma AK, Singh V, Vikas P. Application of nanotechnology as a tool in animal products processing and marketing: An overview. Am J Food Technol. 2012; 7(8): 445-451. doi: 10.3923/ ajft.2012.445.451

13. El Sabry MI, McMillin KW, Sabliov CM. Nanotechnology considerations for poultry and livestock production systems-a review. Annals of Animal Science. 2018; 18(2): 319-334. doi: 10.1515/aoas2017-0047

14. Vinus, Sheoran N. Role of nanotechnology in poultry nutrition. Int J Pure App Biosci. 2017; 5: 1237-1245. doi: 10.18782/23207051.5948

15. Mohapatra P, Swain RK, Mishra SK, Behera T. Effects of dietary nano-selenium supplementation on the performance of layer grower birds. Asian Journal of Animal and Veterinary Advances. 2014; 9(10): 641-652. doi: 10.3923/ajava.2014.641.652

16. Kumar V, Yadav SK. Plant-mediated synthesis of silver and gold nanoparticles and their applications. Journal of Chemical Technology \& Biotechnology. 2009; 84(2): 151-157. doi: 10.1002/jctb.2023

17. Prasad KS, Pathak D, Patel A, Selvaraj K. Biogenic synthesis of silver nanoparticles using Nicotiana tobaccum leaf extract and study of their antibacterial effect. African Journal of Biotechnology. 2011; 10(41): 8122-8130.

18. Prasad R, Swamy VS. Antibacterial activity of silver nanoparticles synthesized by bark extract of Syzygium cumini. Journal of Nanoparticles. 2013; 2013: 6. doi: 10.1155/2013/431218

19. Swamy VS, Prasad R. Green synthesis of silver nanoparticles from the leaf extract of Santalum album and its antimicrobial activity. J Optoelectron Biomed Mater. 2012; 4(3): 53-59.

20. Boulaiz H, Alvarez PJ, Ramirez A, Marchal JA, Prados J, Rodríguez-Serrano, et al. Nanomedicine: Application areas and development prospects. Int J Mol Sci. 2011; 12(5): 3303-3321. doi: 10.3390/ ijms12053303

21. Prasad R, Kumar V, Prasad KS. Nanotechnology in sustainable agriculture: Present concerns and future aspects. African Journal of Biotechnology. 2014; 13(6): 705-713. doi: 10.5897/AJBX2013.13554

22. Dilbaghi N, Kaur H, Kumar R, Arora P, Kumar S. Nanoscale device for veterinary technology: trends and future prospective. Advanced Materials Letters. 2013; 4(3): 175-184. doi: 10.5185/amlett.2012.7399 
23. Ahmadi F, Rahimi F. The effect of different levels of nanoSilver on performance and retention of silver in edible tissues of broilers. World Applied Sciences Journal. 2011; 12(1): 1-4.

24. Razi MK, Maamoury RS, Banihashemi S. Preparation of nanoselenium particles by water solution phase method from industrial dust. International Journal Nano Dimension. 2011; 1(4): 261 267. doi: 10.7508/IJND.2010.04.003

25. Chakravarthi PV, Balaji SN. Applications of nanotechnology in veterinary medicine. Vet World. 2010; 3(10). doi: 10.5455/vetworld.2010.477-480

26. Dian L, Yang Z, Li F, Wang Z, Pan X, Peng X, et al. Cubic phase nanoparticles for sustained release of ibuprofen: Formulation, characterization, and enhanced bioavailability study. Int J Nanomedicine. 2013; 8: 845-54. doi: 10.2147/IJN.S40547

27. King T, Osmond-McLeod MJ, Duffy LL. Nanotechnology in the food sector and potential applications for the poultry industry. Trends in Food Science \& Technology. 2018; 72: 62-73. doi: 10.1016/j. tifs.2017.11.015

28. Ahmadi F, Kordestany AH. Investigation on silver retention in different organs and oxidative stress enzymes in male broiler fed diet supplemented with powder of nanosilver. American-Eurasian Journal of Toxicological Sciences (AEJTS). 2011; 3(1): 28-35.

29. Paleo AJ, Martínez-Boubeta C, Balcells L, Costa CM, Sencadas V, Lanceros-Mendez S. Thermal, dielectrical and mechanical response of $\alpha$ and $\beta$-poly (vinilydene fluoride)/Co-MgO nanocomposites. Nanoscale Res Lett. 2011; 6(1): 1-4. doi: 10.1186/1556276X-6-257

30. Sekhon BS. Nanoprobes and their applications in veterinary medicine and animal health. Research Journal of Nanoscience and Nanotechnology. 2012; 2(1): 1-16. doi: 10.3923/rjnn.2012.1.16

31. Saki A, Salary J. In ovo injection of silver nanoparticles, thyme and savory extract on growth performance and blood parameters in broiler chicks. Animal Sciences Journal (Pajouhesh \& Sazandegi). 2014; 101: 70-78.

32. Kim B-S, Park I-K, Hoshiba T, Jiang H-L,Choie Y-J, Akaike T, et al. Design of artificial extracellular matrices for tissue engineering. Progress in Polymer Science. 2011; 36(2): 238-268. doi: 10.1016/j. progpolymsci.2010.10.001

33. Liao C-D, Hung W-L, Jan K-C, Yeh A-I, Ho C-T, Hwang LS. $\mathrm{Nano} /$ sub-microsized lignan glycosides from sesame meal exhibit higher transport and absorption efficiency in Caco-2 cell monolayer. Food Chemistry. 2010; 119(3): 896-902. doi: 10.1016/j.foodchem.2009.07.056

34. Weiss J, Gibis M, Schuh V, Salminen H. Advances in ingredients and processing systems for meat and meat products. Meat Sci. 2010; 86(1): 196-213. doi: 10.1016/j.meatsci.2010.05.008
35. Zha LY, Xu ZR, Wang MQ, Gu LY. Chromium nanoparticle exhibits higher absorption efficiency than chromium picolinate and chromium chloride in Caco-2 cell monolayers. I Anim Physiol Anim Nutr (Berl). 2008; 92(2): 131-140. doi: 10.1111/j.14390396.2007.00718.x

36. Heller L. Flavor firm uses nanotechnology for new ingredient solutions. Food Navigator News. 2006; 10.

37. Wen H-W, DeCory TR, Borejsza-Wysocki W, Durst RA. Investigation of neutr avidin-tagged liposomal nanovesicles as universal detection reagents for bioanalytical assays. Talanta. 2006; 68(4): 1264-1272. doi: 10.1016/j.talanta.2005.07.032

38. Yadav D, Singh AK, Kumar B, Mahla AS, Singh SK, Patra MK, et al. Effect of n-3 PUFA-rich fish oil supplementation during late gestation on kidding, uterine involution and resumption of follicular activity in goat. Reproduction in Domestic Animals. 2019; 54(12): 1651-1659. doi: $10.1111 /$ rda. 13575

39. Prasad R, Jain V, Varma A. Role of nanomaterials in symbiotic fungus growth enhancement. Current Science. 2010; 99(9): 11891191.

40. Biswal SK, Nayak AK, Parida UK, Nayak P. Applications of nanotechnology in agriculture and food sciences. Int J Sci Innov Discov. 2012; 2(1): 21-36.

41. Awwad AM, Salem NM. Green synthesis of silver nanoparticles by mulberry leaves extract. Nanoscience and Nanotechnology. 2012; 2(4): 125-128. doi: 10.5923/j.nn.20120204.06

42. Scott N. Nanotechnology and animal health. Revue scientifique et technique (International Office of Epizootics). 2005; 24(1): 425-432. doi: 10.20506/rst.24.1.1579

43. Joshua PP, Valli C, Balakrishnan V. Effect of in ovo supplementation of nanoforms of zinc, copper, and selenium on post-hatch performance of broiler chicken. Vet World. 2016; 9(3): 287-294. doi: 10.14202/vetworld.2016.287-294

44. Scott A, Vadalasetty KP, Chwalibog A, Sawosz E. Copper nanoparticles as an alternative feed additive in poultry diet: A review. Nanotechnology Reviews. 2018; 7(1): 69-93. doi: 10.1515/ntrev-2017-0159

45. Scott A, Vadalasetty KP, Łukasiewicz M, Jaworski S, Wierzbicki M, Chwalibog A, et al. Effect of different levels of copper nanoparticles and copper sulphate on performance, metabolism and blood biochemical profiles in broiler chicken. Journal of Animal Physiology and Animal Nutrition. 2018; 102(1): e364-e373. doi: $10.1111 /$ jpn. 12754

46. Smith DM, Simon JK, Baker Jr JR. Applications of nanotechnology for immunology. Nat Rev Immunol. 2013; 13(8): 592-605. doi: $10.1038 /$ nri3488

47. Tripp RA, Alvarez R, Anderson B, Jones L, Weeks C, Chen W. 
Bioconjugated nanoparticle detection of respiratory syncytial virus infection. Int J Nanomedicine. 2007; 2(1): 117-124. doi: 10.2147/ nano.2007.2.1.117

48. Wiley JA, Richert LE, Swain SD, Harmsen A, Barnard DL, Randall TD, et al. Inducible bronchus-associated lymphoid tissue elicited by a protein cage nanoparticle enhances protection in mice against diverse respiratory viruses. PLoS One. 2009; 4(9): e7142. doi: 10.1371/journal.pone.0007142

49. Ghalamkari G, Toghyani M, Tavalaeian E, Landy N, Ghalamkari Z, Radnezhad H. Efficiency of different levels of Satureja hortensis L.(Savory) in comparison with an antibiotic growth promoter on performance, carcass traits, immune responses and serum biochemical parameters in broiler chickens. African Journal of Biotechnology. 2011; 10(61): 13318-13323.

50. Kuzma J. Nanotechnology in animal production-Upstream assessment of applications. Livestock Science. 2010; 130(1-3): 14-24. doi: 10.1016/j.livsci.2010.02.006

51. Mahmoud UT. Silver nanoparticles in poultry production. Journal of Advanced Veterinary Research. 2012; 2(4): 303-306.

52. Matsumura Y, Yoshikata K, Kunisaki S-i, Tsuchido T. Mode of bactericidal action of silver zeolite and its comparison with that of silver nitrate. Appl Environ Microbiol. 2003; 69(7): 4278-4281. doi: 10.1128/AEM.69.7.4278-4281.2003
53. Luo PG, Tzeng T-R, Qu L, Lin Y, Caldwell E, Latour RA, et al. Quantitative analysis of bacterial aggregation mediated by bioactive nanoparticles. Journal of Biomedical Nanotechnology. 2005; 1(3): 291-296. doi: 10.1166/jbn.2005.040

54. Niknamfar AH, Esmaeili H. Reviewing on nanotechnology for creating antimicrobial for chicken feed: Max-min optimization approach. International Journal of Research in Industrial Engineering. 2017; 6(4): 312-327. doi: 10.22105/RIEJ.2017.100933.1021

55. Num S, Useh N. Nanotechnology applications in veterinary diagnostics and therapeutics. Sokoto Journal of Veterinary Sciences. 2013; 11(2): 10-14. doi: 10.4314/sokjvs.v11i2.2

56. Love SA, Maurer-Jones MA, Thompson JW, Lin Y-S, Haynes CL. Assessing nanoparticle toxicity. Annu Rev Anal Chem (Palo Alto Calif). 2012; 5: 181-205. doi: 10.1146/annurev-anchem-062011-143134

57. Rashidi L, Khosravi-Darani K. The applications of nanotechnology in food industry. Critical Reviews in Food Science and Nutrition. 2011; 51(8): 723-730. doi: 10.1080/10408391003785417

58. Dreher KL. Health and environmental impact of nanotechnology: Toxicological assessment of manufactured nanoparticles. Toxicological Sciences. 2004; 77(1): 3-5. doi: 10.1093/toxsci/kfh041 